\title{
Basic Public Services, Population Migration and Regional Economic Growth
}

\author{
Shuying Zhai \\ College of Economics, Jinan University, Guangzhou, China \\ Email: zshinne@163.com
}

How to cite this paper: Zhai, S. Y. (2020). Basic Public Services, Population Migration and Regional Economic Growth. Modern Economy, 11, 777-784.

https://doi.org/10.4236/me.2020.114057

Received: February 23, 2020

Accepted: April 5, 2020

Published: April 8, 2020

Copyright $\odot 2020$ by author(s) and Scientific Research Publishing Inc. This work is licensed under the Creative Commons Attribution International License (CC BY 4.0).

http://creativecommons.org/licenses/by/4.0/

(c) (i) Open Access

\begin{abstract}
The innovation of this paper is to propose a new impact path that by attracting migrant population, basic public services can stimulate national economic growth significantly. Based on the "cost-benefit" theory, this paper takes basic public services into the population migration decision-making model, then builds an endogenous economic growth model by using population immigration as an increase of human capital. Theoretical analysis finds that basic public services can attract people to move in positively and promote regional economic growth indirectly. Based on the above conclusions, this paper presents that, we should increase fiscal transfer payments in backward areas, develop and improve the equalization system of basic public services while adapting to local conditions. And some related policies and statutes need to be published by government at the same time, such as policies of talent attraction and investment promotion policies to promote orderly population flow and balance the distribution of population, to make sure regional economy develops healthily.
\end{abstract}

\section{Keywords}

Basic Public Services, Population Migration, Economic Growth

\section{Introduction}

During the process of China's system reform and industrial structure transformation and upgrading, the surplus labor resources accumulated in urban and rural areas exploded, and large-scale populations moved from rural to urban areas, providing an inestimable impetus for regional economic growth. Especially with the continuous deepening of reform and opening up, household registration control has loosened with the time going, the willingness of population migration has greatly increased. According to the report on the development of 
China's floating population, the amount of China's floating population was only 6.57 million in 1982, and it surged to 253 million by 2014 . The proportion of the total population has increased from $0.65 \%$ to $18.41 \%$. Since 2015 , the scale of the floating population in China has changed from a continuous rise before to a slow decline. And it slowly decreased to 244 million in 2017, which may be due to the identity change that the newly migrated population who have settled in the local area turned into new citizens identity because of the constantly relaxing regional settlement system. It is foreseeable that large-scale population migration will still be an important phenomenon in China's economic and society for a long period in the future. However, where did such a large-scale population migrate? From the perspective of inter-provincial population migration, it is reflected that people migrate mainly from west to east. It must be noted that the floating population in top five cities including Shanghai, Beijing, Shenzhen, Dongguan, and Guangzhou accounted for nearly $25 \%$ of the total floating people in China (Xia, Su, \& Huang, 2015).

It tells us the migrants are more inclined to stay in several big cities especially in Beijing, Shanghai, Guangzhou or Shenzhen. It cannot be denied that abundant human capital brought by large-scale immigration promoted local economic development in the past few decades. But along with that, disadvantages have gradually become apparent, such as serious concentration of population in the inflow region, the heavy pressure of public services, the serious brain drain in the outflow region, the weak economic development, and the serious imbalance in regional development. Facing the downward pressure on the economy and the main contradiction of uneven social development, what effective measures to take to resolve the population pressure in core cities, realize the return of population in less developed regions, and support the high-quality development of the economy have become a real tough challenge for our government. This paper focuses on basic public services, and attempts to study whether the impact of basic public services in promoting economic growth continues to be strong still under the current situation of population agglomeration and unequal basic public services. What is the path basic public services influence economic growth? Whether promoting the level of basic public services in underdeveloped areas can lead to the return of population, promote local economic growth effectively. Clarifying these issues will help to point out the policy direction for local governments under the requirements of high-quality economic development.

\section{Literature Review}

For the impact of basic public services on regional economic growth, most academics believe that a higher level of basic public services will promote regional economic development (Pierre-Richard, 2008; Tamai, 2009). By sorting out existing literature, we can summarize the following mechanism of basic public services to promote economic growth. Firstly, by investing in human capital, such as investment in education, science, health care, and increasing employment op- 
portunities, basic public services can improve quality and ability of local people, and increase human capital accumulation to achieve technology progress, to promote long-term economic growth (Zhang, 2011). Secondly, by reducing precautionary saving, basic public services encourage household consumption, and expand investment to promote domestic consumption and economic growth. Thirdly, by narrowing the gap in individual income, basic public services can promote economic development fairly and build a stable social environment to maintain long-term stable economic growth. Fourthly, by property rights protection and maintenance of market order, basic public services improve transaction efficiency, promote the evolution of division of labor in a high-level and indirectly promote economic growth (Luo, 2008).

The impact of basic public services on economic growth may be multipath. So, by the way of population migration, could improving basic public service levels promote regional economic growth indirectly? Specifically, the new path we put forward in this paper is that, the level of basic public services affects the decision-making of population migration, which affects the amount of net population in the region, but not the quality of the local population, thereby changes the allocation of human capital across regions, and ultimately affects the level of regional economic development. Based on this, this paper needs to clarify the following two issues: the impact of basic public services on population migration decisions, and the relationship between population migration and economic growth.

As for issue I, the first thing we must clarify is that basic public services mainly cover low-level consumer demand areas such as infrastructure, public education, social security, medical care, employment, and public culture. The famous "foot voting theory" was the first to link local public services with population migration behaviors. He believed that residents would choose the area where the combination of public goods and taxation best fits their preferences to live, and by increasing supply of public goods and reducing taxation, the area may attract more migrants. In the classical theory of fiscal decentralization, the provision of public goods as a welfare policy will directly affect the disposable income of individuals, improve the level of consumer utility, and then affect migration decisions. In addition, from the perspective of the production field, public expenditure on infrastructure construction and other aspects can improve the production efficiency of manufacturers, affect the regional average wage level from a macro perspective and encourage population migration (Chang \& Tong, 2015). The existence of the positive influence has also been proven in many empirical studies (Bayoh, Irwin, \& Haab, 2006; Dahlberg, Eklof, Fredriksson, \& Jofre-Monseny, 2012). And it has to be said that basic public services have also spillover effects on neighboring areas according to the existing empirical research findings. However, at the same time, public service supply will require a considerable amount of fiscal funds, which will increase the regional financial burden. Those units whose wages are tied to local financial strength (such as public institutions and government agencies) may have lower wage levels, which may result in population migration in a 
negative way.

The relationship between population migration and economic growth is widely concerned in academia. Along with the industrialization process, the related research mainly focuses on the optimization about the surplus labor forces in the agricultural sector migrating into industrial sector. The influx of labor from rural to urban areas has significantly promoted regional economic growth, and has a significant effect of reducing poverty (Shi \& Li, 2007). More freedom and convenience of population migration given will help the economy to maintain rapid growth in the process of transformation and upgrading.

This paper proposes a new impact path innovatively, that basic public services may stimulate economic growth by attracting population migration. It will be demonstrated systematically through theoretical and empirical methods.

\section{Theoretical Analysis}

Referring to the "cost-benefit" theory proposed by T. W. Schults (1962), this paper takes basic public services into the population migration model and examines the impact of basic public services on population migration, and then takes population migration into the macroeconomic growth model through human capital, and finally gives out the core corresponding theoretical analysis point.

\subsection{Basic Public Services Affect Population Migration}

Migration is an important way for workers to improve their living standards and obtain fair opportunities (Sun, Huang, \& Hong, 2012). Based on the "cost-benefit" population migration theory model proposed by T. W. Schults (1962), we assume on this theoretical model that: firstly, in an economy where the population can flow freely, everyone is an independent rational individual, and make a migration decision by balancing benefits and costs. Secondly, When benefits of move in $\left(U_{i}\right)$ are greater than costs of move out $\left(U_{o}\right)$ including opportunity costs, people may choose to move out. While when benefits of move in $\left(U_{i}\right)$ are less than costs of move out $\left(U_{o}\right)$, people give up moving. Thirdly, Basic public services, as a kind of social public resources, are extensive and non-profit, so they are regarded as a hidden benefit taken into the cost-benefit theory model.

Generally, the benefits brought by migration can be divided into monetary benefits and non-monetary benefits. Monetary benefits include higher wage income $\left(w_{i}\right)$, basic public services $\left(p_{i}\right)$, and regional expenditure levels $\left(e_{i}\right)$ which will weaken the immigration benefits. Non-monetary benefits mainly include subjective feelings such as improved social relationships and higher levels of psychological satisfaction. To simplify the analysis, it is unified as $f_{i}$.

Correspondingly, the cost of moving out includes monetary costs and non-monetary costs. Monetary costs include corresponding opportunity costs such as wage levels $\left(w_{o}\right)$ and basic public services $\left(p_{o}\right)$ in the place of moving 
out, and housing prices $\left(h_{o}\right)$, and travelling expenses $\left(t_{o}\right)$ related to migration distance. Non-monetary costs are mainly the negative emotions $\left(f_{o}\right)$ of being away from relatives and friends psychologically.

$$
\begin{gathered}
U_{i}=\left(w_{i} r_{i}+p_{i} v\right) * d-e_{i}+f_{i} \\
U_{o}=w_{o} r_{o}+p_{o} v-e_{o}-t_{o}+f_{o}
\end{gathered}
$$

$r_{i}$ is the employment rate in the place of immigration, and $r_{o}$ is rate in emigration place, $v$ is the value rate of basic public service. $p_{i} v$ means the monetary value of the basic public service in the immigration place and $p_{o} v$ means in emigration place. $d$ is the discrimination. Due to the existence of China's household registration system, new immigrants will be discriminated against in the process of employment because they do not have a local household registration, which will affect wage levels. At the same time, basic public services are relative to the household registration. There exists different treatment between non-registered population and registered population, so there is a "discount" on basic public services. As can be seen, $0<d<1$. To simplify the analysis here, we assume that discrimination against newly immigrants about both wages and basic public services is in the same degree.

Compared with the benefits and costs of migration, migration decisions are only made when the former exceeds the latter.

$$
U_{i}-U_{o}=\left(p_{i} d-p_{o}\right) v+C_{i, o}
$$

If, $C_{i, o}=w_{i} r_{i} d+w_{o} r_{o}-e_{i}+e_{o}+f_{i}-f_{o}+t_{o}$

It can be seen from the above, when $U_{i}-U_{o}$ is greater than 0 , in other words, $\left(p_{i} d-p_{o}\right) v+C_{i, o}$ is greater than 0 , the decision maker will choose to migrate. Otherwise, if it is less than or equal to 0 , the decision maker will not migrate. The higher level of public services in the place of immigration, the greater probability of relocation, but affected by discrimination, the willingness will be weakened. Therefore, it is concluded that, on the premise of ignoring discrimination and existing free movement of population, higher level of basic public services in the region will attract more population to move in.

\subsection{Basic Public Services, Population Migration and Regional Economic Growth}

China has a unified tax system applied in each area, because local governments do not have the tax legislative power. Under the unified tax system arrangement, every economic entity basically enjoys the same tax treatment. Tiebout's "foot voting" theory states that residents will choose the area where there exits better public goods and less taxation according to their preferences. When there is no difference in tax treatment, the migration behavior of residents will depend on the level of regional public services only. Based on the previous analysis, we set the migration function $M(p)$ as an increasing function of basic public services $(p)$, which represents that the higher level of basic public services are, the larger the scale of net migration becomes. 
The economic growth model under the traditional closed conditions generally assumes that the labor force maintains exogenous growth, that is to say, $\dot{L} / L=n$. $n$ is the natural population growth rate. But it ignores the impact of labor flow between regions. We refer to Solow's economic growth model, take labor flow bringing human capital into the model, and examine the relationship among basic public services, labor flow and regional economic growth.

Suppose the production function is the Cobb-Douglas production function:

$$
Y(t)=F[K(t), A(t) L(t)]=K(t)^{\alpha}(A(t) L(t))^{1-\alpha}
$$

The following are assumptions about input factors. Interregional labor flow will change the growth rate of regional labor input, that is, regional labor growth depends on both the exogenous natural growth rate $(n)$ and the net population migration $(M(p))$ :

$$
\dot{L} / L=n+M(p) / L=n+m(p)
$$

And $m(p)$ is the net population migration rate.

Knowledge grows at a fixed rate:

$$
\dot{A} / A=g
$$

Take human capital carried by labor inflows $(M(p))$ into the capital accumulation equation:

$$
\dot{K}=s Y-\delta K+\theta M(p)
$$

$Y$ is the total output and is used for consumption and investment. $s$ is the proportion of investment and it is exogenous and fixed. Each unit of output used for investment can get one unit of new capital. $\delta$ is the depreciation rate if existing capital. Human capital is taken into model together with physical capital. $\theta$ is the amount of human capital carried by one unit of floating population.

From Equations (4) to (7), we can get the production function of $(t+1)$ period:

$$
Y(t+1)=K(t)^{\alpha}(A(t) L(t))^{1-\alpha} \cdot \mathrm{e}^{\frac{s Y-\delta K}{K} \alpha+(n+g)(1-\alpha)+\frac{\theta M(p)}{K} \alpha+(1-\alpha) m(p)}
$$

To clarify the relationship between basic public services and economic growth, we get:

$$
\begin{aligned}
& \frac{\partial(Y(t+1)-Y(t))}{\partial p} \\
& =K(t)^{\alpha}(A(t) L(t))^{1-\alpha} \cdot \mathrm{e}^{C+\frac{\theta M(p)}{K} \alpha+\frac{M(p)}{L}(1-\alpha)} \cdot\left(\frac{\theta \alpha}{K}+\frac{1-\alpha}{L}\right) \cdot \frac{\partial M(p)}{\partial p}
\end{aligned}
$$

Equation (9) shows that there is a positive relationship between basic public services and economic growth. That is, better regional basic public services more can attract population to move in more effectively, promote the concentration of human capital in specific regions, and finally promote the rapid growth of regional economy. And it can be noted that the greater $\theta$ (the amount of human capital carried by a unit of floating population) is, the stronger influence of pop- 
ulation migration in promoting economic growth, which means higher quality (healthier constitution and higher education) the region's migrating population has, can stimulate rapid economic growth, this is why governments are so actively promoting preferential policies for talent introduction nowadays.

\section{Conclusions and Policy Recommendations}

This paper constructs a population migration model based on the cost-benefit theory. After theoretical analysis and study, it is found that the higher level of basic public services is, the more population it can attract to move in. Then it proposes a new economic growth model that labor force including basic public service levels is taken into. Theoretical analysis shows basic public services can promote regional economic growth through the population migration mechanism. For further study, we can collect more data about national public services, migrant population and economic growth from different cities to make further empirical research, and we have not done that in this paper. According to the theoretical research, we can get the following policy recommendations based on the above research.

\subsection{Provide Basic Public Services Equally}

Improve of basic public services with high quality in undeveloped areas and promote equalization of basic public services. Although the average level of basic public services in the central and western regions of China has been steadily increasing year by year, the gap compared with the eastern region is still obvious. This has caused severe population loss and weak economic growth in the undeveloped regions, and has thus entered the embarrassing dilemma of "becoming poorer and poorer". At the same time, it makes core cities in the east have to face the overpopulation called "big city disease". Therefore, efforts should be made to urge the improvement of basic facilities in undeveloped areas. Each locality should provide proper basic public services in accordance with the characteristics of economic and social development in its jurisdiction, improve regional education, medical care, social security, cultural construction, and optimize the supply structure of public goods. It is also needed to improve local government spending preferences, reduce vanity projects, and attract talent flowing back, to provide development environment and reserve high-quality talents for advanced industries, to promote regional economic development vigorously, to achieve coordinated economic development in the eastern, central and western regions.

\subsection{Increase Fiscal Transfer Payments in Backward Areas}

It is undeniable that development of basic public services is inseparable from regional economic growth. Without sufficient local financial resources to support, improving the level of basic public services is impossible absolutely. First of all, local governments in undeveloped areas are already relatively tight in financial resources. Blindly requiring local governments to increase investment in basic public services without giving sufficient central transfer funds may lead to a 
more serious local debt crisis.

\subsection{Implement Talent and Investment Policies}

Improving basic public services can promote local economic growth by attracting population to flow back, but the attraction of basic public services to migrants is often relatively lagging, so a stimulus point is needed, talents policy. Talent is the mainstay of economic development. In the crazy battle for attracting talent, it is clear that most of the undeveloped regions lack relevant talent policies. And therefore, considering with the actual local financial capacity, it is necessary to increase the intensity of rewards and support for entrepreneurship, and actively attract high-quality talents. However, the more important is to make sure talents settle down. All of these must be supported by corresponding industries. Local governments must actively attract investment, encourage entrepreneurship by entrepreneurship training and providing entrepreneurship subsidies, and promote the regional economy with high quality.

\section{Conflicts of Interest}

The author declares no conflicts of interest regarding the publication of this paper.

\section{References}

Bayoh, I., Irwin, E. G., \& Haab, T. (2006). Determinants of Residential Location Choice: How Important Are Local Public Goods in Attracting Homeowners to Central Locations. Journal of Regional Science, 46, 97-120. https://doi.org/10.1111/j.0022-4146.2006.00434.x

Chang, S. W., \& Tong, Y. (2015). From Income Promotion to Basic Public Service Attraction: On the Leading Motivation of Inter Provincial Population Flow in China. Public Finance Research, 3, 45-52.

Dahlberg, M., Eklof, M., Fredriksson, P., \& Jofre-Monseny, J. (2012). Estimating Preferences for Local Public Services Using Migration Data. Urban Studies, 49, 319-336. https://doi.org/10.1177/0042098011400769

Luo, Y. M. (2008). Infrastructure Construction, Transaction Cost and Economic Growth. Contemporary Economic Management, 1, 14-18.

Pierre-Richard, A. (2008). Fiscal Policy and Endogenous Growth with Public Infrastructure. Oxford Economic Paper, 60, 57-87. https://doi.org/10.1093/oep/gpm018

Shi, Y. B., \& Li, G. P. (2007). Evaluation of the Effect of Labor Migration on Anti-Poverty in Rural Areas. China Rural Economy, S1, 20-26.

Sun, S. B., Huang, W., \& Hong, J. J. (2012). Why Is Free Migration of Labor So Important? Based on the Perspective of Intergenerational Income Flow. Economic Research, 5, 147-159.

Tamai, T. (2009). Variety of Products, Public Capital, and Endogenous Growth. Economic Modelling, 26, 251-255. https://doi.org/10.1016/j.econmod.2008.07.003

Xia, Y. R., Su, J. H., \& Huang, W. (2015). Where Does the Floating Population Gather? Urban Characteristics and Changing Trend of Inflow Place. Population and Economy, 3, 13-22.

Zhang, X. (2011). Public Service and Economic Growth: A Normative Study. Southwest Finance, 4, 14-16. 